\title{
Anesthetic Care During Lateral Thoracic Expansion for Asphyxiating Thoracic Dystrophy
}

\author{
Mineto Kamata $^{\text {a, d }}$, Roby Sebastian ${ }^{\text {a }}$, Aymen Naguib ${ }^{a}$, b, Joseph D. Tobias ${ }^{a}$, b, c
}

\begin{abstract}
Jeune syndrome or asphyxiating thoracic dystrophy (JATD) is a rare autosomal recessive disorder with an estimated incidence of 1 in 100,000 to 130,000 live births. The typical phenotype of JATD is osteochondrodysplasia (narrow thorax and shorted ribs) in association with short limb dwarfism. The thoracic dysplasia results in respiratory insufficiency, usually requiring tracheostomy and chronic mechanical ventilation beginning in infancy and childhood. Lateral thoracic expansion is one surgical procedure that has been described in an attempt to enlarge the thoracic cage and alleviate the progressive respiratory failure. In addition to respiratory involvement, patients with JATD may have other co-morbid conditions involving the kidneys, pancreas, liver, and eyes. Given the underlying thoracic dysplasia and other associated comorbid conditions, the intraoperative care of such patients can be challenging. We present two patients with JATD who presented for lateral thoracic expansion. Previous reports of the intraoperative care of such patients are reviewed and options for anesthetic care are discussed.
\end{abstract}

Keywords: Pediatric anesthesia; Jeune syndrome; Asphyxiating thoracic dystrophy; Lateral thoracic expansion

\section{Introduction}

Jeune syndrome or asphyxiating thoracic dystrophy (JATD) was first described in 1954 by Jeune et al [1]. It is a rare, autosomal recessive disorder with an estimated incidence varying

Manuscript accepted for publication June 07, 2016

aDepartment of Anesthesiology \& Pain Medicine, Nationwide Children's Hospital, Columbus, OH, USA

${ }^{b}$ Department of Anesthesiology \& Pain Medicine, The Ohio State University College of Medicine, Columbus, OH, USA

'Department of Pediatrics, Nationwide Children's Hospital \& The Ohio State University College of Medicine, Columbus, OH, USA

${ }^{\mathrm{d} C o r r e s p o n d i n g ~ A u t h o r: ~ M i n e t o ~ K a m a t a, ~ D e p a r t m e n t ~ o f ~ A n e s t h e s i o l o g y ~ \& ~}$ Pain Medicine, Nationwide Children's Hospital, 700 Children's Drive, Columbus, OH 43205, USA. Email: Mineto.Kamada@Nationwidechildrens.org

doi: http://dx.doi.org/10.14740/jmc2549w from 1 in 100,000 to 1 in 130,000 live births [2]. The typical characteristic of JATD is an osteochondrodysplasia characterized by a narrow thorax and shortened ribs in association with short-limb dwarfism. The thoracic dysplasia results in progressive respiratory insufficiency with up to $60-70 \%$ of homozygous carriers dying from respiratory failure or chronic pulmonary infections. Despite the skeletal deformity affecting the thoracic cavity, pathologic studies suggest that alveolar and lung growth potential may be normal [2]. Although the clinical manifestations of respiratory insufficiency vary in magnitude from lethal to subclinical forms, comorbid conditions associated with JATD may lead to severe organ dysfunction affecting the kidney, pancreas, liver, and eyes in later years [3].

A number of surgical techniques have been reported in an attempt to limit the impact of the thoracic deformities on respiratory function. Lateral thoracic expansion (LTE) enlarges the thoracic cage in patients with JATD by separating, reconstructing, and lengthening the ribs to expand the thoracic cage. Although LTE remains a safe and effective procedure for this patient population, there are few reports discussing the intraoperative care with particular attention to acute, intraoperative changes in respiratory function. We present two patients with JATD presenting for LTE surgery. Previous reports of the intraoperative care of such patients are reviewed. Options for anesthetic care are discussed with a focus on acute changes in intraoperative ventilator settings and compliance changes.

\section{Case Reports}

Institutional Review Board approval for case reports involving two or fewer patients was not required by Nationwide Children's Hospital (Columbus, $\mathrm{OH}$ ).

\section{Case 1}

A 19-month-old, $8.1 \mathrm{~kg}$ boy presented for general anesthesia for left LTE. He had a history of skeletal dysplasia, hypoplastic thoracic dystrophy, scoliosis, hip dysplasia, craniosynostosis, and pulmonary hypoplasia. Past surgical history included a right LTE at 7 months of age following a tracheostomy and craniosynostosis repair at 16 months of age. He was admitted to the hospital from home 1 day prior to surgery, requiring 
Table 1. Ventilation Parameters of Cases 1 and 2

\begin{tabular}{|c|c|c|c|c|}
\hline Parameters & At incision & After division of ribs & After attachment of plates & At the end of surgery \\
\hline \multicolumn{5}{|l|}{ Case 1} \\
\hline $\mathrm{PIP}\left(\mathrm{cm} \mathrm{H}_{2} \mathrm{O}\right)$ & 25 & 31 & 31 & 31 \\
\hline $\mathrm{Vt}(\mathrm{mL} / \mathrm{kg})$ & 10 & 13 & 13 & 12 \\
\hline $\mathrm{RR}(\mathrm{bpm})$ & 26 & 26 & 26 & 26 \\
\hline $\operatorname{PEEP}\left(\mathrm{cm} \mathrm{H}_{2} \mathrm{O}\right)$ & 6 & & & \\
\hline $\mathrm{FiO}_{2}(\%)$ & 39 & 39 & 40 & 40 \\
\hline $\mathrm{SpO}_{2}(\%)$ & 100 & & & \\
\hline $\mathrm{EtCO}_{2}(\mathrm{~mm} \mathrm{Hg})$ & 43 & 50 & 50 & 47 \\
\hline $\mathrm{I}: \mathrm{E}$ & $1: 2$ & & & \\
\hline \multicolumn{5}{|l|}{ Case 2} \\
\hline $\mathrm{PIP}\left(\mathrm{cm} \mathrm{H}_{2} \mathrm{O}\right)$ & 32 & 32 & 31 & 31 \\
\hline $\mathrm{Vt}(\mathrm{mL} / \mathrm{kg})$ & 13 & 13 & 14 & 13 \\
\hline RR (bpm) & 23 & 25 & 22 & 22 \\
\hline $\operatorname{PEEP}\left(\mathrm{cm} \mathrm{H}_{2} \mathrm{O}\right)$ & 10 & & & \\
\hline $\mathrm{FiO}_{2}(\%)$ & 54 & 56 & 55 & 75 \\
\hline $\mathrm{SpO}_{2}(\%)$ & 100 & & & \\
\hline $\mathrm{EtCO}_{2}(\mathrm{~mm} \mathrm{Hg})$ & 34 & 33 & 32 & 44 \\
\hline $\mathrm{I}: \mathrm{E}$ & $1: 2$ & & & \\
\hline
\end{tabular}

Pressure-limited ventilation was used during the case. PIP: peak inspiratory pressure; Vt: expiratory tidal volume; RR: respiratory rate; bpm: breathes/minute; PEEP: positive end expiratory pressure; $\mathrm{FiO}_{2}$ : fraction of inspired oxygen; $\mathrm{SpO}_{2}$ : pulse oximeter oxygen saturation; EtCO $\mathrm{E}_{2}$ : end tidal $\mathrm{CO}_{2} ; \mathrm{I}: \mathrm{E}:$ inspiratory to expiratory time ratio.

chronic mechanical ventilation $24 \mathrm{~h}$ a day via tracheostomy using a Respironics Trilogy home ventilator. His preoperative oxygen saturation was $100 \%$ with synchronized intermittent mandatory ventilation (SIMV) in the pressure-controlled mode. Preoperative ventilator settings included: respiratory rate (RR) 26 breathes/min, peak inspiratory pressure (PIP) 30 $\mathrm{cm} \mathrm{H}_{2} \mathrm{O}$, positive end expiratory pressure (PEEP) $12 \mathrm{~cm} \mathrm{H}_{2} \mathrm{O}$, pressure support $16 \mathrm{~cm} \mathrm{H}_{2} \mathrm{O}$, inspiratory time $0.7 \mathrm{~s}$, and $\mathrm{FiO}_{2}$ $30 \%$. Mechanical ventilation was achieved through a $4.0 \mathrm{~mm}$ cuffed tracheostomy tube. Preoperative laboratory evaluation revealed a hemoglobin of $14.7 \mathrm{~g} / \mathrm{dL}$ and a hematocrit of $43.2 \%$. Prior to surgery, a 24-gauge intravenous cannula was placed and he was transported to the operating room. After American Society of Anesthesiologists (ASA) monitors were applied, anesthesia was induced with sevoflurane (end-tidal concentration $2 \%$ ) and fentanyl $(3 \mu \mathrm{g} / \mathrm{kg})$. Neuromuscular blockade was provided by rocuronium $(1.5 \mathrm{mg} / \mathrm{kg})$. At the beginning of the surgery, intercostal blockade with $0.5 \%$ of bupivacaine was applied by the surgeon. There was no significant change in the vital signs during anesthetic induction. Following anesthetic induction, he was turned to the right lateral decubitus position and mechanical ventilation initiated with the anesthesia machine ventilator: PIP $24 \mathrm{~cm} \mathrm{H}$ O, RR 26 breathes/min, PEEP $10 \mathrm{~cm} \mathrm{H}_{2} \mathrm{O}$, inspiratory/expiratory time (I:E) ratio $1: 2$, and $\mathrm{FiO}_{2} 40 \%$. The expiratory volume varied from 12 to $14 \mathrm{~mL} /$ $\mathrm{kg}$. Anesthesia was maintained with isoflurane (end-tidal concentration 1\%), fentanyl (total intraoperative dose of $15.4 \mu \mathrm{g}$ / $\mathrm{kg}$ ), and rocuronium. Intraoperatively, the ventilator settings were adjusted to maintain a tidal volume of approximately 10 $\mathrm{mL} / \mathrm{kg}$. The settings for mechanical ventilation are listed in Table 1 at various times including 1) prior to incision, 2) after division of the ribs, 3) after attachment of plates, and 4) at the completion of surgery. At each of these points, pressure-controlled ventilation was provided to achieve normocapnia. Following the surgical procedure, the patient was transported to the cardiothoracic intensive care unit (CTICU). Postoperative analgesia was provided by nurse-controlled analgesia (NCA) with fentanyl, rescue doses of enteral oxycodone, and scheduled intravenous acetaminophen followed by ketorolac. He was discharged from the CTICU and hospital on postoperative days 1 and 7, respectively. At discharge, his oxygen saturation was $100 \%$ with SIMV in the pressure-controlled mode. The ventilator settings included: RR 26 breathes/min, PIP $30 \mathrm{~cm}$ $\mathrm{H}_{2} \mathrm{O}$, PEEP $12 \mathrm{~cm} \mathrm{H}_{2} \mathrm{O}$, pressure support $16 \mathrm{~cm} \mathrm{H}_{2} \mathrm{O}$, inspiratory time $0.7 \mathrm{~s}$, and $\mathrm{FiO}_{2} 30 \%$.

\section{Case 2}

A 16-month-old, $7.1 \mathrm{~kg}$ boy with JATD presented for general anesthesia for right LTE. He had a complex medical history including JATD requiring chronic mechanical ventilation via tracheostomy using a Respironics Trilogy home ventilator, pulmonary hypertension, and bilateral clubfeet. Past surgical history included a Nissen fundoplication and gastrostomy tube insertion at 6 months of age. He had been admitted for ap- 
proximately 3 months prior to surgery due to pseudomonas aerugenosa bacteremia, tracheitis, and pneumonia. His preoperative oxygen saturation was $98 \%$ with SIMV pressurecontrolled ventilation: RR 26 breathes/min, PIP $30 \mathrm{~cm} \mathrm{H} \mathrm{H}_{2} \mathrm{O}$, PEEP $10 \mathrm{~cm} \mathrm{H}_{2} \mathrm{O}$, PS $18 \mathrm{~cm} \mathrm{H}_{2} \mathrm{O}$, pressure support $18 \mathrm{~cm}$ $\mathrm{H}_{2} \mathrm{O}$, inspiratory time $0.4 \mathrm{~s}$, and $\mathrm{FiO}_{2} 30 \%$. Preoperative laboratory evaluation revealed a hemoglobin of $11.1 \mathrm{~g} / \mathrm{dL}$ and a hematocrit of $34.5 \%$. Prior to the surgery, a 24-gauge intravenous cannula was placed. Following premedication with midazolam, he was transported to the operating room. After ASA standard monitors were applied, anesthesia was induced with sevoflurane (end-tidal concentration 2-3\%) and fentanyl $(1.5 \mu \mathrm{g} / \mathrm{kg})$. Neuromuscular blockade was achieved with rocuronium $(1.5 \mathrm{mg} / \mathrm{kg})$. There was no significant change in the vital signs during anesthetic induction. Following anesthetic induction, the $3.5 \mathrm{~mm}$ cuffed tracheostomy tube was changed to $3.5 \mathrm{~mm}$ cuffed endotracheal tube and he was turned to the left lateral decubitus position. Mechanical ventilation was initiated with the anesthesia machine ventilator using the following settings: PIP $24 \mathrm{~cm} \mathrm{H}_{2} \mathrm{O}, \mathrm{RR} 25$ breaths/min, PEEP $10 \mathrm{~cm}$ $\mathrm{H}_{2} \mathrm{O}$, I:E ratio $1: 2$, and $\mathrm{FiO}_{2} 55 \%$. The expiratory tidal volume was $109 \mathrm{~mL}(15 \mathrm{~mL} / \mathrm{kg})$. Anesthesia was maintained with isoflurane (end-tidal concentration 1\%) and fentanyl (total intraoperative dose of $8.5 \mu \mathrm{g} / \mathrm{kg}$ ). Intermittent doses of rocuronium were administered as needed to provide neuromuscular blockade. The settings for mechanical ventilation at the same points as case 1 are listed in Table 1. Following the surgical procedure, the patient was admitted to the CTICU. Postoperative analgesia was provided by nurse controlled analgesia with fentanyl and scheduled intravenous acetaminophen and ketorolac. The remainder of his postoperative course was unremarkable. At discharge, his oxygen saturation was $99 \%$ with SIMV in the pressure-controlled mode. The ventilator settings included: RR 26 breathes/min, PIP $30 \mathrm{~cm} \mathrm{H}_{2} \mathrm{O}$, PEEP $10 \mathrm{~cm}$ $\mathrm{H}_{2} \mathrm{O}$, pressure support $18 \mathrm{~cm} \mathrm{H}_{2} \mathrm{O}$, inspiratory time $0.6 \mathrm{~s}$, and $\mathrm{FiO}_{2} 30 \%$.

\section{Discussion}

JATD is a disease process that may have effects in multiple organ systems. The respiratory symptoms vary widely from respiratory failure requiring tracheostomy placement and chronic mechanical ventilation from infancy to phenotypes that have mild respiratory involvement that may improve with age [4]. Given that the majority of JATD patients die from respiratory failure in early childhood, one of the keys in the perioperative management of these patients is to limit further respiratory deterioration. Involvement of the chest wall with limited growth and expansion significantly impairs lung growth, leading to pulmonary hypoplasia with restricted thoracic volumes thereby placing these patients at risk for perioperative barotrauma and pneumothorax during positive-pressure ventilation [5]. Although achievement of intraoperative ventilation by pressure-controlled ventilation with lower tidal volumes (6 - 8 $\mathrm{mL} / \mathrm{kg})$ has been reported, higher tidal volumes $(10 \mathrm{~mL} / \mathrm{kg})$ were achieved in both of our patients with an acceptable PIP of $30 \mathrm{~cm} \mathrm{H}_{2} \mathrm{O}[6,7]$. In addition to the potential to result in barotrauma, higher PIPs may result in increased intra-thoracic pressure and impaired venous return resulting in reduced cardiac output. Given these concerns, pressure-limited ventilation should be adjusted to keep the PIP $\leq 30 \mathrm{~cm} \mathrm{H}_{2} \mathrm{O}$. Lengthening the inspiratory time and the use of high respiratory rates may allow for an effective tidal volume and minute ventilation while limiting PIP [8].

During the preoperative assessment, the home ventilation settings should be noted and attempts are made to mimic this pattern of ventilation intraoperatively. Given that the restriction to pulmonary expansion is related to the rigid restriction of the thoracic cavity, it is likely that minimal changes in resistance or compliance can be expected during general anesthesia and the use of neuromuscular blocking agents. This was the case in both of our patients as we noted no clinically significant changes intraoperatively in respiratory compliance with general anesthesia and neuromuscular blockade. Similarly, no immediate changes were noted in compliance immediately following LTE.

In any patient with respiratory insufficiency regardless of the cause, chronic hypoxemia and hypercarbia may result in chronic pulmonary hypertension, cor pulmonale, and right heart failure. Given these concerns, a preoperative echocardiogram is suggested to evaluate pulmonary artery pressures. In patients with pulmonary hypertension, mechanical ventilation and intraoperative therapies may need to be adjusted to minimize the risk of acute elevations of pulmonary artery pressure $[9,10]$.

In theory, alveolar growth may continue up until 8 years of age [11]. In patients with JATD, pathologic studies suggest that alveolar and lung growth are potentially normal, and that pulmonary impairment is secondary to the narrowing of the thoracic cage. Therefore, it is theorized that if the thorax is expanded, further lung growth can be expected. Various surgical techniques have been suggested for thoracic expansion in patients with JATD including sternal splitting, posterolateral rib cage expansion by placing plates, and vertical expandable prosthetic titanium rib (VEPTER) opening thoracotomy [1214]. The primary goal of these procedures is to increase the thoracic volume and allow for lung expansion and growth.

LTE, the surgical procedure performed in our two patients, has been used to safely and effectively expand the thoracic cage in children with JTAD $[15,16]$. The procedure involves separation of a segment of ribs from their underlying periosteum followed by staggered osteotomies with spreading and expansion maintained by bringing together the long segments of adjacent ribs and attaching them with plates. Although there have been reported improvements of respiratory function after surgery, there are limited or no data evaluating acute intraoperative changes in resistance and complicance $[15,16]$. While anecdotal experience noted an intraoperative improvement in respiratory compliance during bilateral thoracoplasty and thoracotomy, ventilation returned to baseline after prosthesis placement [6]. In our case series, we noted no clinically significant improvement or deterioration in pulmonary resistance and compliance intraoperatively, thereby further suggesting that the true benefit of the procedure is to allow for subsequent increased lung growth.

Given the pre-existing impaired respiratory function, 
postoperative management for JATD patients should focus on respiratory management with providing adequate pain control. Inadequate pain control can result in decreased respiratory excursion with rapid respiratory rates leading to loss of functional residual capacity (FRC) and atelectasis with its antecedent effects on pulmonary compliance. Atelectasis and a decrease in FRC may also elevate pulmonary artery pressure. Aggressive pulmonary toilet with suctioning and clearance of secretions is also important to limit the risks of nosocomial pneumonia. Postoperative analgesia for our patients was achieved by a multimodal analgesia technique including intercostal nerve blockade intraoperatively under direct vision by the surgeon, nurse-controlled analgesia with fentanyl, and adjunctive agents including acetaminophen or non-steroidal anti-inflammatory agents. Since both of our patients had a tracheostomy and were chronically dependent on home mechanical ventilation, they were transferred to the CTICU and mechanical ventilation continued postoperatively. With effective analgesia and aggressive pulmonary toilet, both transitioned quickly back to their home ventilation regimen.

In addition to involving the thoracic cavity, the skeletal dysplasia of JATD may also involve the spine. The thoracic and lumbar spines appear relatively normal in height and width, while cervical spine abnormalities can be life-threatening [17]. The posterior arch of $\mathrm{C} 1$ may curve anteriorly and compress the spinal cord. As such issues may impact airway management and intraoperative positioning, the cervical spine of patients with JATD should be evaluated preoperatively. Although instability is uncommon, if cervical stenosis is suspected on routine radiographic imaging, computed tomographic imaging or flexion/extension MRI studies of the cervical cord should be obtained. In addition to cervical cord compression, central apnea has been reported secondary to $\mathrm{C} 1$ compression [18].

The majority of patients with JATD have respiratory involvement either immediately following birth or develop respiratory insufficiency during the first few years of life, requiring tracheostomy and chronic mechanical ventilation. The severity of the thoracic deformity is a main factor of prognosis as the majority of patients will die from respiratory failure within the first few years. However, in specific phenotypes, the thoracic malformation and respiratory problems may be less severe, even decreasing with age [19]. Patients who survive the first year of life, may manifest extrathoracic comorbidities including renal, hepatic, gastrointestinal, and retinal dysfunction.

Renal involvement has been noted in approximately $40 \%$ of patients with JATD, beginning in early infancy [20-22]. Progressive renal dysfunction results from a ciliary defect in the nephrons resulting in tubulointerstitial nephropathy and cystic changes with tubular dysfunction, dilation, and fibrosis [23]. Given the primary tubular involvement, an inability to concentrate the urine is frequently noted. Additional clinical symptom includes polyuria, proteinuria, an increase in blood urea nitrogen (BUN) and creatinine, and hypertension $[4,21]$. Renal failure remains the primary cause of death in patients with JATD between the ages of 3 and 10 years. In older patients, preoperative screening should include an evaluation of electrolytes, BUN, creatinine, and urinalysis. Perioperatively, urine output may be a poor indicator of intravascular volume status, as a concentrating defect is frequently noted with polyuria and isosthenuria.

Hepatic involvement occurs in up to $30 \%$ of patients with JATD. Hepatic involvement includes prolonged neonatal jaundice, elevated liver enzymes, hepatomegaly, portal hypertension, hyperplasia of the bile ducts and hepatic fibrosis [24]. In most patients, hepatic pathological changes are noted only at autopsy and clinical signs of hepatic insufficiency are rare. However, neonates with cholestasis seem to have a poorer prognosis $[25,26]$. As hepatic involvement with fibrosis may be noted in the patients who survive early infancy, an evaluation of hepatic function including hepatic enzymes, bilirubin, and coagulation function is suggested prior to surgical intervention in older patients.

Other comorbid conditions have been reported involving the eye and the gastrointestinal (GI) tract. Eye abnormalities including optic nerve hypoplasia, retinal dystrophy, abnormal retinal pigmentation, nystagmus, myopia, and progressive visual field loss are seen in $15 \%$ of the patients with JATD [21, 27, 28]. Age of occurrence has been variable. JATD can also occasionally be associated with GI malformations including cystic changes of the pancreas with fibrosis, Hirschsprung's disease, and malrotation as a manifestation of the ciliopathy $[29,30]$.

JATD is an autosomal recessive disorder primarily impairing respiratory function with thoracic restriction impairing lung growth. Given the underlying thoracic dysplasia and early mortality due to respiratory impairment, preoperative management for the patients with JATD should be focused on respiratory management and minimizing iatrogenic damage and perioperative deterioration of respiratory function. Comorbid conditions associated with JATD may affect the kidney, pancreas, liver, and eyes. Preoperative identification and evaluation of associated comorbid conditions which can impact the perioperative management is suggested with optimizing of end-organ function prior to surgical intervention.

\section{Conflicts of Interest}

None.

\section{References}

1. Jeune M, Carron R, Beraud C, Loaec Y. [Polychondrodystrophy with fatal throacic blockage]. Pediatrie. 1954;9(4):390-392.

2. Oberklaid F, Danks DM, Mayne V, Campbell P. Asphyxiating thoracic dysplasia. Clinical, radiological, and pathological information on 10 patients. Arch Dis Child. 1977;52(10):758-765.

3. Schmidts M. Clinical genetics and pathobiology of ciliary chondrodysplasias. J Pediatr Genet. 2014;3(2):46-94.

4. Tuysuz B, Baris S, Aksoy F, Madazli R, Ungur S, Sever L. Clinical variability of asphyxiating thoracic dystrophy (Jeune) syndrome: Evaluation and classification of 13 patients. Am J Med Genet A. 2009;149A(8):1727-1733.

5. Borland LM. Anesthesia for children with Jeune's syn- 
drome (asphyxiating thoracic dystrophy). Anesthesiology. 1987;66(1):86-88.

6. Saletti D, Grigio TR, Tonelli D, Ribeiro Junior OD, Marini F. Case report: anesthesia in patients with asphyxiating thoracic dystrophy: Jeune syndrome. Rev Bras Anestesiol. 2012;62(3):424-431.

7. Buget MI, Ozkan E, Edipoglu IS, Kucukay S. Anesthetic Approach for a Patient with Jeune Syndrome. Case Rep Anesthesiol. 2015;2015:509196.

8. Tobias JD. Conventional mechanical ventilation. Saudi J Anaesth. 2010;4(2):86-98.

9. Abman SH, Hansmann G, Archer SL, Ivy DD, Adatia I, Chung WK, Hanna BD, et al. Pediatric Pulmonary Hypertension: Guidelines From the American Heart Association and American Thoracic Society. Circulation. 2015;132(21):2037-2099.

10. Shukla AC, Almodovar MC. Anesthesia considerations for children with pulmonary hypertension. Pediatr Crit Care Med. 2010;11(2 Suppl):S70-73.

11. Thurlbeck WM. Postnatal human lung growth. Thorax. 1982;37(8):564-571.

12. Barnes ND, Hull D, Milner AD, Waterston DJ. Chest reconstruction in thoracic dystrophy. Arch Dis Child. 1971;46(250):833-837.

13. Phillips JD, van Aalst JA. Jeune's syndrome (asphyxiating thoracic dystrophy): congenital and acquired. Semin Pediatr Surg. 2008;17(3):167-172.

14. Gadepalli SK, Hirschl RB, Tsai WC, Caird MS, Vanderhave KL, Strouse PJ, Drongowski RA, et al. Vertical expandable prosthetic titanium rib device insertion: does it improve pulmonary function? J Pediatr Surg. 2011;46(1):77-80.

15. Davis JT, Heistein JB, Castile RG, Adler B, Mutabagani $\mathrm{KH}$, Villalobos RE, Ruberg RL. Lateral thoracic expansion for Jeune's syndrome: midterm results. Ann Thorac Surg. 2001;72(3):872-877; discussion 878.

16. Davis JT, Long FR, Adler BH, Castile RG, Weinstein S. Lateral thoracic expansion for Jeune syndrome: evidence of rib healing and new bone formation. Ann Thorac Surg. 2004;77(2):445-448.

17. Campbell RM, Jr. Spine deformities in rare congenital syndromes: clinical issues. Spine (Phila $\mathrm{Pa}$ 1976). 2009;34(17):1815-1827.

18. Congiu P, Puligheddu M, Gioi G, Marica M, Pani C, Piga
$\mathrm{S}$, Marrosu F, et al. Respiratory sleep disorders in Jeune syndrome: a case description. Arch Ital Biol. 2015;153(23):167-171.

19. de Vries J, Yntema JL, van Die CE, Crama N, Cornelissen EA, Hamel BC. Jeune syndrome: description of 13 cases and a proposal for follow-up protocol. Eur J Pediatr. 2010;169(1):77-88.

20. Lehman AM, Eydoux P, Doherty D, Glass IA, Chitayat D, Chung BY, Langlois S, et al. Co-occurrence of Joubert syndrome and Jeune asphyxiating thoracic dystrophy. Am J Med Genet A. 2010;152A(6):1411-1419.

21. Keppler-Noreuil KM, Adam MP, Welch J, Muilenburg A, Willing MC. Clinical insights gained from eight new cases and review of reported cases with Jeune syndrome (asphyxiating thoracic dystrophy). Am J Med Genet A. 2011;155A(5):1021-1032.

22. Amirou M, Bourdat-Michel G, Pinel N, Huet G, Gaultier J, Cochat P. Successful renal transplantation in Jeune syndrome type 2. Pediatr Nephrol. 1998;12(4):293-294.

23. Poyner SE, Bradshaw WT. Jeune syndrome: considerations for management of asphyxiating thoracic dystrophy. Neonatal Netw. 2013;32(5):342-352.

24. Yerian LM, Brady L, Hart J. Hepatic manifestations of Jeune syndrome (asphyxiating thoracic dystrophy). Semin Liver Dis. 2003;23(2):195-200.

25. Pawlowska J, Dobrzanska A, Migdal M. Cholestasis of different clinical severity in children with Jeune syndrome. E\&C Hepatol. 2007;3:41-44.

26. Reddy SN, Seth BA, Colaco P. Jeune syndrome with neonatal cholestasis. Indian J Pediatr. 2011;78(9):1151-1153.

27. Wilson DJ, Weleber RG, Beals RK. Retinal dystrophy in Jeune's syndrome. Arch Ophthalmol. 1987;105(5):651657.

28. Casteels I, Demandt E, Legius E. Visual loss as the presenting sign of Jeune syndrome. Eur J Paediatr Neurol. 2000;4(5):243-247.

29. Brueton LA, Dillon MJ, Winter RM. Ellis-van creveld syndrome, Jeune syndrome, and renal-hepatic-pancreatic dysplasia: separate entities or disease spectrum? J Med Genet. 1990;27(4):252-255.

30. Hall T, Bush A, Fell J, Offiah A, Smith V, Abel R. Ciliopathy spectrum expanded? Jeune syndrome associated with foregut dysmotility and malrotation. Pediatr Pulmonol. 2009;44(2):198-201. 